Saudi Journal of Humanities and Social Sciences

Abbreviated Key Title: Saudi J Humanities Soc Sci

ISSN 2415-6256 (Print) | ISSN 2415-6248 (Online)

Scholars Middle East Publishers, Dubai, United Arab Emirates

Journal homepage: https://saudijournals.com/sjhss

Original Research Article

\title{
Mobile Assisted Language Learning in Learning Arabic as a Second Language in Saudi Arabia
}

\author{
Ahmed AlQarni ${ }^{1,2 *}$, Andy Bown ${ }^{2}$, Darren Pullen², Jennifer Masters ${ }^{2}$ \\ ${ }^{1}$ Al-Imam Mohammad Ibn Saud Islamic University, Riyadh, Saudi Arabia \\ ${ }^{2}$ University of Tasmania, Launceston TAS, Australia
}

DOI: $10.36348 /$ sjhss.2020.v05i02.009

| Received: 07.02.2020 | Accepted: 22.02.2020 | Published: 29.02.2020

*Corresponding author: Ahmed AlQarni

\section{Abstract}

This paper reports the results of an investigation into the use of mobile assisted language learning for learning Arabic as a second language in the context of Saudi Arabian higher education. The purpose of this study was to explore what kinds of mobile learning devices second language Arabic learners and their teachers currently use and how they use these devices for learning the Arabic language. This mixed-methods study employed a sequential explanatory design, incorporating questionnaires and semi-structured interviews with second language students and their teachers. A total of 154 teachers and 492 students participated in the quantitative phase of the study whilst 14 teachers and 16 students took part in the qualitative phase. The results showed that smartphones the most widely used mobile device among second language Arabic learners and their teachers. Their current use of mobile devices was focused on social media apps such as YouTube and WhatsApp to support Arabic language learning.

Keywords: Second language learning, mobile devices, Arabic language, mobile assisted learning.

Copyright @ 2020: This is an open-access article distributed under the terms of the Creative Commons Attribution license which permits unrestricted use, distribution, and reproduction in any medium for non-commercial use (NonCommercial, or CC-BY-NC) provided the original author and source are credited.

\section{INTRODUCTION}

The use of technology in education has received much attention in recent decades. Television and radio programmes and audio/videotapes have been used in distance learning since the 1970s [1]. As technology developed, new learning and teaching methodologies, such as web-based learning, virtual classrooms and technology-enhanced learning, became part of a technology-driven methodology for learning called e-learning (electronic learning) [2-4].

These days, the latest generation of smartphones and tablets, which have faster cellular connectivity and increased Wi-Fi capabilities, have ushered in a new way of learning known as Mobile Learning (m-learning) [5]. M-learning places the emphasis on continuity and spontaneity across different contexts of use. Although many researchers have attempted to define the concept of m-learning, there is still no definitive agreement on its definition [6, 7]. While the debate continues, it is now generally agreed that m-learning comprises four central constructs: learning pedagogies, technological devices, context and social interactions. Berge and Muilenburg [8] have integrated these four components and defined $\mathrm{m}$ learning as "learning across multiple contexts, through social and content interactions, using personal electronic devices" (p.4).

In addition to the lack of a common definition of m-learning, there are opposing views on the use of mobile devices in language learning [9]. According to an optimistic viewpoint, the use of mobile learning offers language learners an opportunity for experiential learning using authentic materials and increases interaction with a variety of self-chosen participants. Jee [10] claims that "the use of these technologies addresses many of the major challenges of second language acquisition (SLA), such as: comprehensible input or " $i+1$ " [11], the interaction hypothesis [12, 13], corrective/facilitative feedback [14, 15], and learner autonomy [16]." The ubiquity and accessibility of such devices has the potential to assist language learning by enhancing students' vocabulary learning [17, 18], listening skills [19], communication skills and motivation [20].

In contrast, the pessimistic viewpoint highlights the factors that impede learners from using mobile devices in language learning. Shudong and Higgins [21] analysed the psychological, pedagogical, and technical barriers of using mobile technologies in 
learning. These researchers concluded that psychologically speaking, students are not yet familiar with mobile learning. Pedagogically speaking [22], point out that although "mobility and portability" have been used to justify using mobile devices, this "often seems not to be fully exploited in the design of mobile assisted language learning (MALL) activities." Technically speaking, these technologies still put up barriers, such as limited screen size and inconvenient means of inputting text when compared with desktop computers.

A number of studies have reviewed the integration of mobile devices with learning and teaching [23, 24, 5]. Sung, Chang, \& Liu [25], performed a meta-analysis and synthesis of the effects of integrated mobile devices on teaching and learning of 110 studies published between 1993-2013. They concluded that "the effect of using mobile devices in education is better than using desktop computers or not using mobile devices" [25].

The field of mobile device assisted language learning is broadly referred to as MALL, which can be defined as "learning mediated via handheld devices and potentially available anytime, anywhere" [22]. A handheld device is "any device that is small, autonomous and unobtrusive enough to accompany us in every moment" [26], such as mobile phones or handheld computers such as Tablets.

Studies have also confirmed the benefits of integrating technologies with language learning. Darmi and Albion [27] reviewed 33 empirical studies, published between 2004 and 2013, on the integration of mobile devices in language learning methodologies and found that mobile phones were widely used by learners of second language learning. In spite of the readiness of language teachers to integrate the use of mobile phones in teaching methods, learners were quicker to adopt the use of this technology to support their learning process than their teachers [28].

The use of mobile technologies in the learning and teaching of Arabic as a second language, in both formal and informal contexts, from the perspective of learners and teachers in Saudi Arabia has yet to be investigated. To date, it seems only two studies, which were conducted in America [29, 30], have investigated the use of mobile technology in the context of learning Arabic as a second language. Abedalla [29] investigated the perceptions about the use of mobile apps of 40 students at three small universities in Pennsylvania. The participants were graduates and undergraduate students with an elementary level of Arabic, both male and female, and chosen by convenience sampling techniques. Ahmed [30] examined strengths and weaknesses of classroom activities specifically designed for portable technology (iPad/MacBook Pro) in enhancing reading and listening proficiency for four
US military services. Thirty students participated; both males and females and aged between 18-25 years. These military learners were divided into three focus groups of 10 students each. The two studies found a positive impact for the use of mobile technology on Arabic language learning.

Since little research has been undertaken into MALL in Arabic language learning, this study explores the role of MALL in learning the Arabic language in the context of higher education in Saudi Arabia. More specifically, it aims to address the following objectives.

\section{OBJECTIVE OF THE STUDY}

1. To discover what kind of mobile devices and applications are being used by second language (L2) Arabic learners and their teachers?

2. To achieve a greater understanding of how second language Arabic learners and their teachers at seven Saudi universities currently use their mobile devices for learning Arabic.

\section{METHODS AND MATERIALS Study Design and Setting}

In Saudi Arabia, seven university institutes have programmes to teach Arabic as a second language. The Foreign Service Institute (FSI) has categorised the Arabic language as being one of the most difficult languages to learn and estimates that it requires approximately 2,200 hours or 88 weeks to achieve a general level of proficiency [31]. None of the programmes offered by the institutes comprises that number of hours; on average, these Institutions offer 1,410 hours of Arabic language instruction. Technology, "if used wisely, can play a major role in enhancing L2 learners' contact with the target language" [32]. The target population for this study is L2 Arabic teachers and their Arabic language learning students at seven universities in Saudi Arabia. These universities are Imam Muhammad Ibn Saud Islamic University, King Saud University, Princess Nourah Bint Abdulrahman University, King Abdulaziz University, Umm Al Qura University, Islamic University, and Qassim University.

This study used a sequential explanatory design incorporating two phases: a quantitative phase and a qualitative phase [33]. The reason for choosing this approach was that the quantitative data were intended to provide a general picture of the current use of mobile devices in L2 of Arabic at these seven universities while the qualitative data would be used to help explain the results obtained from the quantitative data [34].

\section{Participants}

The participants in the study were teachers and learners of L2 Arabic from the seven Saudi Arabian universities. For quantitative data, a probability sampling technique was used in attempt to attain 
representativeness when sampling from a wider population, posing a reduced risk of bias when compared to a non-probability sample [35]. The form of probability sampling used is known as random stratified sampling. The size of the group was determined on the basis of a confidence level of $95 \%$ and a confidence interval of $5 \%$. For qualitative data, purposive sampling was used. The number and type of participants for each phase are shown below in Table-1.

Table-1: Table of sample

\begin{tabular}{|l|l|l|}
\hline Type of Data & No of Teachers & No of Learners \\
\hline Quantitative & 154 & 492 \\
\hline Qualitative & 14 & 16 \\
\hline
\end{tabular}

\section{Data Collection}

A teacher questionnaire, a learner questionnaire and semi-structured interviews were used to collect the data. The questionnaires were used to discover what types of mobile device, platform, and mobile applications teachers and learners currently use, while semi-structured interviews were employed to gain a deeper understanding of how these choices were made. The data were collected through personal visits to the sample universities. After receiving the ethical approvals from the University of Tasmanian and the Saudi Ministry of Education, both questionnaires were distributed among L2 Arabic learners and their teachers. Qualitative data were collected via semi-structured telephone interviews.

\section{DATA ANALYSIS}

The quantitative questionnaire data were analysed first using descriptive statistical techniques to find out the types of mobile device, platform, and mobile applications currently used by L2 Arabic learners and their teachers. Second, the qualitative data obtained from the interviews were analysed using theoretical thematic analysis to explain quantitative findings to get a better understanding of MALL in L2 Arabic in Saudi Arabia. ATLAS.ti 8 software was used to facilitate the data analysis.

\section{RESULTS AND DISCUSSION}

This section presents the results and discussion pertaining to the quantitative and qualitative data. The section provides the results obtained from the quantitative data first, followed by those arising from the qualitative data.

\section{Mobile devices and platform}

As indicated in Figures 1 and 2, quantitative data revealed that $96 \%$ of L2 Arabic learners and $97 \%$ of their teachers used a mobile device irrespective of device type. Smartphone devices were used by vast of majority of L2 Arabic learners and their teachers followed by laptops (See Figure-1). In addition, Windows was the most popular operating system for laptops among teachers, while the Macintosh operating system was favoured by L2 Arabic learners. For smartphones, the Android platform was the most commonly used by both learners and their teachers (See Figure-2).

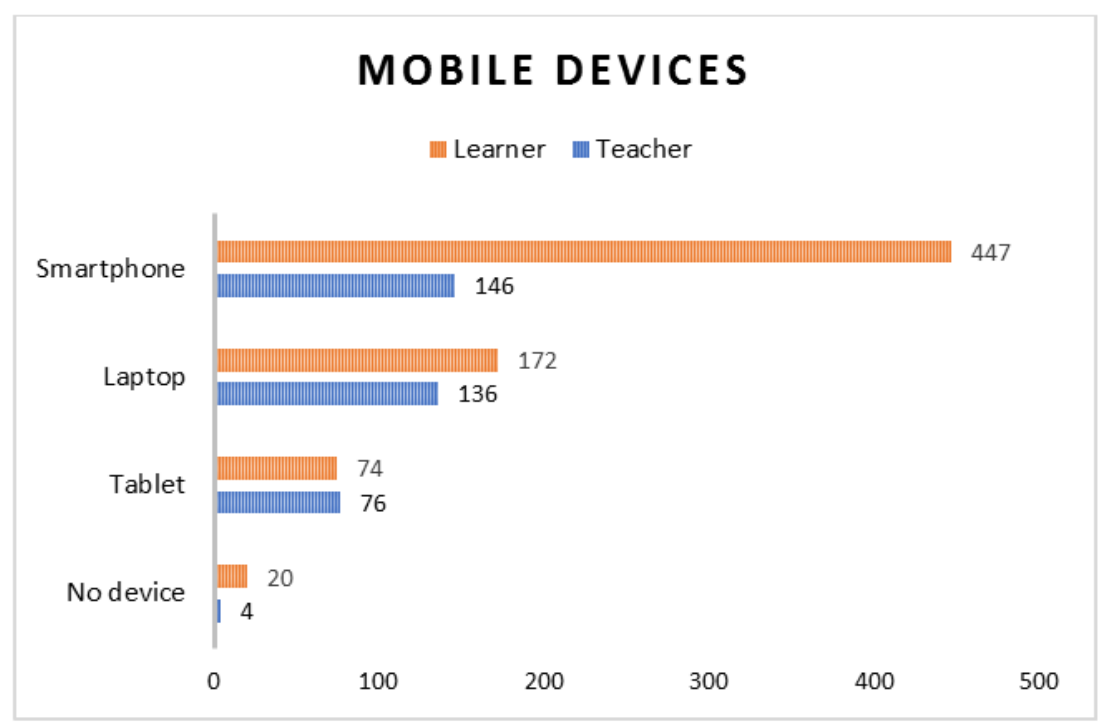

Fig-1: Mobile devices used by L2 Arabic learners and their teachers 


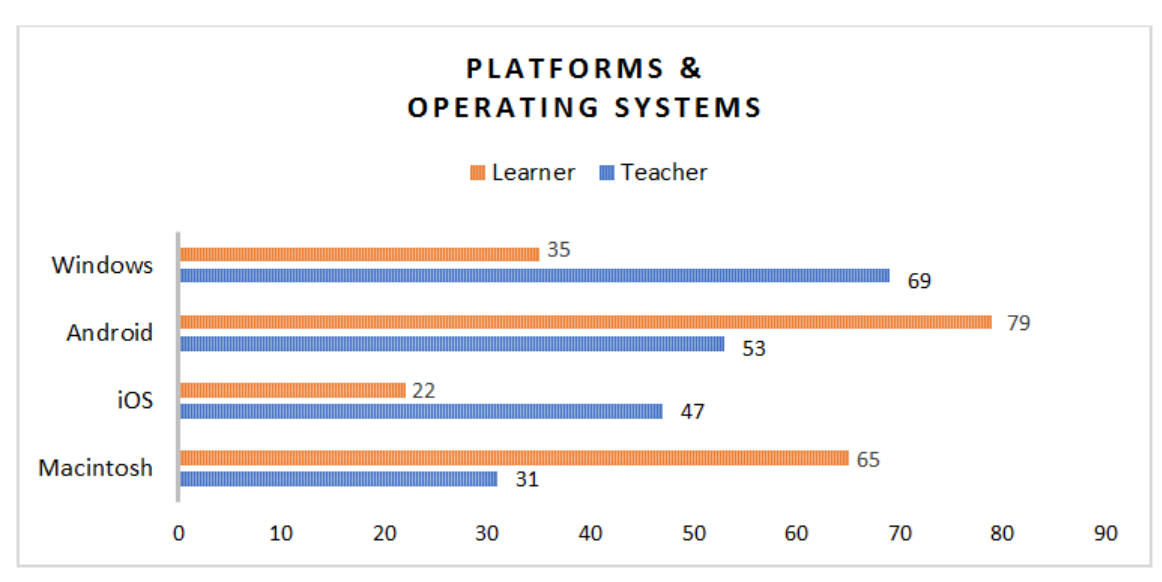

Fig-2: Platforms and operating systems used by L2 Arabic learners and their teachers

Qualitative analysis of the interview data showed that the L2 Arabic learners and their teachers identified different factors which affected their choices of mobile devices, platforms, and operating systems. These factors were categorised into three themes: financial, technical, and security.

Financial reasons mentioned by L2 Arabic learners and their teachers in their interviews included the purchase price of a device, the cost of repairs and replacement parts, and the cost of applications. The financial factor was the most frequent reason mentioned by L2 Arabic learners and their teachers, most of whom indicated that the iPhone was far more expensive than equivalent Android devices. For instance, one of the teachers noted:

The price gap between Android devices in general and the iPhone is huge in Saudi Arabia. I could get two Android devices for the price of one iPhone! For instance, my current smartphone is Huawei P9. When I bought it, it was cheaper than the iPhone by $1100 \mathrm{SR}$, and I don't think that there is a technical advantage in the iPhone worth that price gap

Similarly, one learner stated the following:

As you know, I was granted a scholarship from this university to study Arabic language and a bachelor's degree afterward. I have a limited living allowance which is $850 \mathrm{SR}$ per month. This amount would not help to buy a new smartphone form Apple.

Technical reasons indicated by L2 Arabic language learners and their teachers, who owned Apple devices, included connecting their computers to projectors, smartboards, and university Wi-Fi networks. For example, one of the interviewees explained that:

I have been a Mac user for years. When I tried to use it in my classroom, I found it difficult to connect my device to the classroom's projector and smartboard, as the device's output and cables are different. I had to buy my own cables and some adaptors out of my own pocket.
Security was the third factor affecting L2 Arabic language learners' and their teachers' choices of mobile devices. For instance, one of the teachers stated:

I believe that iOS is more secure than Android. This is based on my continuous reading of technical reports. For instance, a while ago, I read that Google discovered many apps in Google Play violated privacy policy and collected data with no permission from users. Even though some of these apps had reached high downloads, Google removed them.

\section{Another Interviewee Added}

I have chosen MacBook Pro as a laptop because it's more secure. My MacBook Pro been with me for years. It still works great. Didn't slowdown and I did not have to erase it at all. While my friends have complained many times about their windows laptops. It had many issues with virous

In conclusion, from the interview data, Android smartphones were widely used by L2 Arabic learners and teachers predominantly due to their low purchase cost. The Windows operating system was the most common between L2 Arabic teachers, as some universities provide free Windows laptops, and it was the only operating system supported by IT departments at the seven universities. Three major themes: financial, technical, and security, emerged from the interview data as the significant factors determining learners' and teachers' choice of mobile device.

\section{Current Use of Mobile Devices}

Quantitative data illustrated that YouTube was the most commonly used mobile application among L2 Arabic language teachers, followed by Almaany dictionary, which is a multilingual application, and WhatsApp, while Almaany dictionary was the most used application by L2 Arabic learners, followed by WhatsApp and YouTube (See Figure-3 below). Surprisingly, not a single Arabic language application was mentioned by the teachers and learners. 


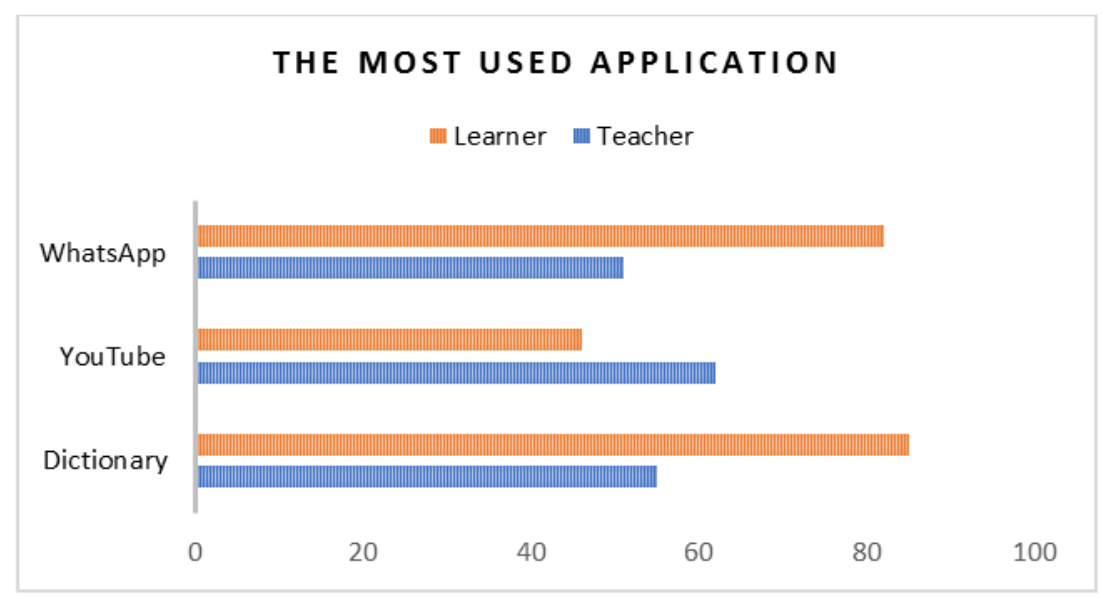

Fig-1: The most used application

Interview questions aimed to find out why no Arabic language application was mentioned by L2 Arabic language learners and their teachers. Both L2 Arabic learners and their teachers were asked how they used some social media applications, such as YouTube and WhatsApp, in their Arabic language teaching and whether they had heard about other applications that taught Arabic such as Arabic Alphabet by TenguLogi or Learn Arabic by Bravolol both applications available on Google Play and iTunes stores.

Three themes emerged from learners and teachers' interviews explaining why they were not using applications that taught Arabic in their teaching. These themes were the lack of available applications, the lack of the relevant content within applications, and institutional policy.

Lack of available applications was mentioned by the vast majority of L2 Arabic learners and teachers. They believed that the number of applications which taught Arabic was minimal in app stores. As a result, they tended to use some social applications for learning, such as YouTube. One of the teachers said,

Applications that teach Arabic are very limited in the app stores, so I often use social media apps for learning. For example, I use YouTube for listening skill. So, I put a video from a news channel followed by some questions to assess their understating

\section{One of the learners added,}

I often use YouTube to help me in Arabic language learning because there are no useful applications. Some students who graduated from our institute launched their channels on YouTube to teach the Arabic language, especially syntax. Their lessons are in the Arabic language and sometimes they use English vocabulary or phrases for assistance

Lack of relevant content within applications was seen by L2 Arabic learners and their teachers as a reason for not using them in their teaching. They believed that applications which taught Arabic were limited to basic Arabic contents, such as beginner vocabulary or bilingual dictionary apps. Some of the L2 Arabic teachers indicated that they found during their search in app stores that most of the results were "very basic apps". They described "very basic apps" as any applications which are designed primarily for native Arabic children and which teach students the Arabic alphabet and simple Arabic words.

A while ago, I did a search on Google Play about learning Arabic. The results were kids' apps, Arabic Alphabet and some simple Arabic words. It did not seem that these applications were designed by linguists or educational organisations. I believed that Arabic language applications are very limited in comparison to other languages applications, such as English language

Institutional policy was the third reason for some L2 Arabic learners and teachers for not using applications which taught Arabic. Some L2 Arabic teachers indicated that it was not allowed to use external curriculums.

In our institute, we use a book series called " $\mathrm{Al}$ Arabiyyah Bayna Yadayk". We are obligated to follow the units' description and the book series, so I do not use any applications except $\mathrm{CDs}$ attached to $\mathrm{Al}$ Arabiyyah Bayna Yadayk.

Some L2 Arabic learners mentioned that their institutes did not allow them to use mobile devices in class. They added, teachers are not willing to help or advise. The teachers are committed to using the printed books only.

In my institute, we cannot use mobile devices while teachers in the classroom. Some teachers believe we cannot concentrate in the lesson while we are using mobile devices. None of my teachers has mentioned mobile application or website to help us in Arabic learning. 
In conclusion, both sets of data revealed that L2 Arabic learners and their teachers were using Dictionary, YouTube, and WhatsApp in their Arabic language learning. Three reasons emerged from the interviews to explain why no Arabic language applications had been mentioned. The reasons were the lack of available applications, the lack of relevant content within applications, and institutional policies.

\section{DISCUSSION \\ Mobile Devices and Platform}

One of the critical success factors for mobile learning is mobile device ownership [36]. To achieve this, there are two main models for providing mobile technologies. These two models are 'bring your own device' (BYOD) or organization provided device (OPD) [37]. Al-shehri [38] indicated that the Arab world is suitable and effective context for mobile learning due to the widespread use of mobile devices. In Saudi Arabia, 99\% of individuals are using a mobile phone and around $70 \%$ are using a smartphone [39]. In this study, it was interesting to find that $97 \%$ of L2 Arabic teachers and $96 \%$ of L2 Arabic learners owned a mobile device irrespective of device type and most of them had more than one device. This widespread use of mobile devices among L2 Arabic language learners and their teachers in Saudi Arabia could potentially maximize the possibility of success for mobile language learning.

In this study, L2 Arabic language learners and their teachers were found to be using various mobile devices, platforms, and operating systems. This variety of platforms and software has implications for the design and development of mobile language learning materials and applications. For instance, Farley et al., [40] illustrated that different operating systems may manage files differently, so materials should be in PDFs or doc, .xls, or ppt formats for laptops users, as many students are using software packages that do not work with the Office Open XML formats such as docx [40]. In regard to mobile applications, there are three main categories of mobile apps irrespective of the type of mobile platform [41]. These are native apps, web apps, and hybrid apps. Each type of application has advantages and disadvantages in terms of performance, cost, internet requirements, notifications etc [41].

\section{Current Use of Mobile Devices}

L2 Arabic language learners' and their teachers' current use of mobile devices was focused on social media apps such as YouTube and WhatsApp or Dictionary to support Arabic learning. None of the participants, L2 Arabic learners and teachers, mentioned any Arabic language application or website. From the interviews, it was apparent that this was due to the lack of available applications, the lack of relevant content within applications, and institutional policies.
In fact, there were 19 applications which teach the Arabic language [42], and two online Arabic programmes called "Interactive Arabic" and "ArabicOnline". "Interactive Arabic" was launched by King Saud University in Saudi Arabia and was available from Google Play and the App Store, and "Arabic-Online" launched by Saudi Electronic University. "ArabicOnline", as an example, has 796 interactive videos, 6,320 pictures, 12,000 sound files, 10,067 exercises. The program is comprised of 16 levels and achievement tests are indexed to the end of each of 6 stages [43].

It was clear that a lack of awareness of the mobile applications and online programmes which were available for Arabic language learning among L2 Arabic learners and their teachers had affected to some extent the way that mobile devices were being used.

\section{CONCLUSION}

Mobile devices were widely owned and used by L2 Arabic learners and their teachers. The current use of mobile devices was focused on social media applications and dictionaries. It was clear that there was a lack of knowledge among L2 Arabic learners and their teachers concerning the range of mobile applications and online programmes available for Arabic language learning, and that this had affected the way that mobile devices were being used to some extent. Arabic languages institutes can play an important role to maximize the possibility of success for mobile language learning in Arabic as a second language. For example, they could renew institutional polices to enable teachers and students to use third party language learning applications once they have been approved by the institutions or universities IT and teaching bodies.

The findings of this study revealed the wide ownership and usage of mobile devices. Future research on MALL in L2 Arabic needs to explore L2 Arabic learners and their teacher's perspective on the use of MALL and it would be meaningful to find out what factors influence their attitude of MALL in L2 Arabic.

\section{REFERENCES}

1. Harting, K., \& Erthal, M. J. (2005). History of distance learning. Information Technology, Learning, and Performance Journal, 23(1), 35.

2. Jochems, W., van Merriënboer, J. J. G., \& Koper, R. (2004). Integrated E-learning: Implications for Pedagogy, Technology and Organization. Retrieved from https://books.google.com.au/books?id=SatjBnj6iN $\mathrm{AC}$

3. Mason, R., \& Rennie, F. (2006). Elearning: The Key Concepts. Retrieved from https://books.google.com.au/books?id=WoV2QgA ACAAJ

4. Pullen, D. (2013). Doctors online: learning using an internet based content management 
system, International Journal of Education and Development using Information and Communication Technology, 9(1):50-63.

5. Pullen, D., Swabey, K., Abadooz, M., \& Sing, T. (2015). Pre-service teachers' acceptance and use of mobile learning in Malaysia, Australian Educational Computing, 30(1):1-14.

6. Crompton, H. (2013). A historical overview of mobile learning: Toward learner-centered education. Handbook of Mobile Learning, 3-14.

7. Kukulska-Hulme, A. (2009). Will mobile learning change language learning? ReCALL, 21(02), 157165.

8. Berge, Z. L., \& Muilenburg, L. Y. (2013). Handbook of Mobile Learning. Retrieved from https://books.google.com.au/books?id=sg_rugAA CAAJ

9. Stockwell, G. (2008). Investigating learner preparedness for and usage patterns of mobile learning. ReCALL, 20(03), 253-270.

10. Jee, M. J. (2011). Web 2.0 technology meets mobile assisted language learning. IALLT Journal of Language Learning Technologies, 41(1), 161175.

11. Krashen, S. D. (1985). The input hypothesis: Issues and implications. Addison-Wesley Longman Ltd.

12. Long, M. H. (1983). Native speaker/non-native speaker conversation and the negotiation of comprehensible input1. Applied linguistics, 4(2), 126-141.

13. Long, M. (1996). The role of the linguistic environment in second language acquisition. Handbook of second language acquisition.

14. Gass, S. (1997). 1997: Input, interaction, and the second language learner. Mahwah, NJ: Lawrence Erlbaum.

15. Long, M. H., Inagaki, S., \& Ortega, L. (1998). The role of implicit negative feedback in SLA: Models and recasts in Japanese and Spanish. The modern language journal, 82(3), 357-371.

16. Benson, P. (2010). Measuring autonomy: Should we put our ability to the test. Testing the untestable in language education, 77-97.

17. Alzahrani, H. (2016). Examining the effectiveness of utilizing mobile technology in vocabulary development for language learners. Browser Download This Paper.

18. Ogata, H., Yin, C., El-Bishouty, M. M., \& Yano, Y. (2010). Computer supported ubiquitous learning environment for vocabulary learning. International Journal of Learning Technology, 5(1):5-24.

19. Rahimi, M., \& Soleymani, E. (2015). The impact of mobile learning on listening anxiety and listening comprehension. English Language Teaching, 8(10), 152.

20. Cooney, G., \& Keogh, K. A. (2007). Use of mobile phones for language learning and assessment for learning, a pilot project. Proceedings of the 6th Annual International Conference on Mobile Learning, Melbourne, Australia.

21. Shudong, W., \& Higgins, M. Limitations of Mobile Phone Learning. , Proceedings of the IEEE International Workshop on Wireless and Mobile Technologies in Education $\S$ (2005).

22. Kukulska-Hulme, A., \& Shield, L. (2008). An overview of mobile assisted language learning: From content delivery to supported collaboration and interaction. ReCALL, 20(03), 271-289.

23. Fleischer, H. (2012). What is our current understanding of one-to-one computer projects: A systematic narrative research review. Educational Research Review, 7(2), 107-122.

24. Hwang, G. J., Chu, H. C., Lin, Y. S., \& Tsai, C. C. (2011). A knowledge acquisition approach to developing Mindtools for organizing and sharing differentiating knowledge in a ubiquitous learning environment. Computers \& Education, 57(1), 1368-1377.

25. Sung, Y. T., Chang, K. E., \& Liu, T. C. (2016). The effects of integrating mobile devices with teaching and learning on students' learning performance: A meta-analysis and research synthesis. Computers \& Education, 94, 252-275.

26. Trifonova, A., \& Ronchetti, M. (2003). A general architecture for m-learning.

27. Darmi, R., \& Albion, P. (2014). A Review of Integrating Mobile Phones for Language Learning. International Association for Development of the Information Society. Retrieved from http://www.mlearning-conf.org/

28. Traxler, J. (2005). Defining mobile learning. IADIS International Conference Mobile Learning, 261-266.

29. Abedalla, R. W. (2015). Students' perceptions of the use of mobile applications technology in learning Arabic as a second language. Robert Morris University.

30. Ahmed, E. (2015). Modern standard Arabic learners' views about the effect of portable technology on L2 learning proficiency in listening and reading at the Defense Language Institute Foreign Language Center. Argosy University/San Francisco Bay Area.

31. ELL. (2015). Language Difficulty Ranking. Retrieved from http://www.effectivelanguagelearning.com/langua ge-guide/language-difficulty

32. Blake, R. J. (2013). Brave new digital classroom: Technology and foreign language learning. Georgetown University Press.

33. Creswell, J. W. (2013). Research design: Qualitative, quantitative, and mixed methods approaches. Sage publications.

34. Ivankova, N. V, Creswell, J. W., \& Stick, S. L. (2006). Using Mixed-Methods Sequential Explanatory Design: From Theory to Practice. 
Field Methods, 18(1), 3-20.

35. Cohen, L., Manion, L., \& Morrison, K. (2013). Research methods in education. Routledge.

36. Alrasheedi, M., \& Capretz, L. F. (2015). Determination of critical success factors affecting mobile learning: A meta-analysis approach. Turkish Online Journal of Educational Technology.

37. Handal, B., Ritter, R., \& Marcovitz, D. (2014). Implementing large scale mobile learning school programs: To BYOD or not to BYOD. EdMedia+ Innovate Learning, 796-801. Association for the Advancement of Computing in Education (AACE).

38. Al-shehri, S. (2012). Contextual language learning: The educational potential of mobile technologies and social media.

39. General Authority for Statistics. (2018). ICT Access and Usage by Households and Individuals Survey. General Authority for Statistics. Retrieved November

8 , 2019, from https://www.stats.gov.sa/en/952

40. Farley, H., Murphy, A., Johnson, C., Carter, B., Lane, M., Midgley, W., ... Koronios, A. (2015). How Do Students Use Their Mobile Devices to Support Learning? A Case Study from an Australian Regional University. Journal of Interactive Media in Education. https://doi.org/10.5334/jime.ar

41. Litayem, N., Dhupia, B., \& Rubab, S. (2015). Review of Cross-Platforms for Mobile Learning Application Development. International Journal of Advanced Computer Science and Applications. https://doi.org/10.14569/ijacsa.2015.060105

42. Heil, C. R., Wu, J. S., Lee, J. J., \& Schmidt, T. (2016). A review of mobilel language learning applications: Trends, challenges, and opportunities. The EuroCALL Review, 24(2), 3250.

43. Arabic-Online. (n.d.). About Arabic Online Progam. Retrieved November 11, 2019, from https://www.arabic-online.net/copy-of-about. 